\title{
MAIMÓNIDES (1135-1204) \\ LA VIGENCIA DE SU MENSAJE
}

\author{
Meir Ben Ytzchak \\ The Lookstein Center \\ Bar llan University \\ meirben@hoimail.com
}

\begin{abstract}
RESUMEN
Este artículo, parte de un trabajo más amplio, destaca los aportes de Maimónides, Ramban, a la cultura judeoespañola sefardita en general y, en particular, al desarrollo de la ciencia médica en la España Medieval.

Después de un resumen histórico biográfico, señala la vinculación entre religión y medicina manifestada en su práctica médica. Concluye con un par de relatos tradicionales sobre la vida del Rabino en la corte musulmana.
\end{abstract}

Palabras Clave: España medieval, sefardíes, Maimónides, medicina.

\begin{abstract}
This paper, part of a larger work, underlines the contributions of Maimonides, Ramban, to sephardic jewish-spanish culture in general and particularly to the development of medical science in Medieval Spain.

After a historical and biographic sketch, it points to the relations between religion and medicine as shown by his medical practice. As a conclusion it offers a pair of traditional narratives on the life of the Rabbi in the muslim court.
\end{abstract}

Key Woros: Medieval Spain, sephardics, Maimonides, medicine.

\section{LA SITUACIÓN EN LA PENÍNSULA IBÉRICA}

En la península ibérica, muchos hombres de ciencia fueron de origen latino. La cultura árabe se justifica porque la gran mayoria de las obras escritas por hombres de esa civilización lo fue en lengua árabe, aunque también se escribió en persa, siriaco y hebreo. Por citar algunos ejemplos se encuentra que el astrónomo Al-Tabarí era iraní; la famosa familia de médicos lbn Bahtyasa era nestoriana, como lo fue Mesue Mayor y Hunian Ben Isaac, mientras que otro gran médico era pagano. El matemático al-Juarismi era persa; los astrónomos al-Fargani eran turcomanos y al-Batari era de Harran, mientras que al-Habas era de Mesopotamia. Los famosos 
médicos Rhazes y al-Biruni eran persas; Ibn Sina (Avicena) procedía de Turquestán y al-Haytan (Halazen) era iraquí; Isaac Israelí y al-Gazar eran judíos; Ibn Rushd (Averroes) y Maimónides eran de Córdoba.

La historia cultural y médica de los judíos en España se puede dividir en tres épocas:

1) Bajo el dominio musulmán, la cultura y la medicina judeo-española se manifiestan como una época de esplendor.

2) Bajo el dominio de los reinos cristianos en proceso de expansión, los sabios judíos florecen durante los siglos XII y XIII, sufriendo posteriormente persecución y represiones que limitan su actividad.

3) Después de la expulsión de los judios en España en 1492 y de Portugal en 1497, aparecen los nuevos cristianos y los que se mantienen fieles a su fe y emigran a África y Asia.

La tolerancia de los emires y luego califas omeyas hizo de España el refugio de los judíos. La ciencia y la cultura judía se enriquecieron. Los gaonim o sabios judíos de Babilonia mantenian correspondencia con los rabinos y sabios de los centros españoles, como Lucena (cerca de Córdoba) y Barcelona. La Academia Talmúdica de Lucena, fundada en el siglo IX, florecía aún en el siglo XII.

\section{EL AUGE DE LA CULTURA JUDIA A PARTIR DEL SIGLO X. MAIMÓNIDES (RAMBAN)}

El renacimiento cultural judio empezó en el siglo X, bajo Abderramán III, que asumió en 929 el título de califa en Córdoba. La ciudad de Córdoba se convirtió en este siglo en la ciudad más civilizada de Europa.

Durante la Edad Media, el hombre de ciencia judía combinaba los estudios tanto religiosos como seculares y estos últimos incluian filosofia, matemáticas, astronomía, astrología y medicina. No era extraño que un judio fuera, al mismo tiempo, médico y rabino. La combinación de rabino y doctor era similar a la del médico y sacerdote.

No cabe duda de que el médico más eminente de esta época judeo-española fue Maimónides (Moisés Ben Maimón), nacido en Córdoba en el año 1135, en las postrimerias del Califato de Occidente.

Maimónides no solo fue un médico eminente, sino que es considerado como la máxima luminaria del pensamiento judaico. Diríase que fue, en plena Edad Media, un precursor de los hombres del Renacimiento: humanista, filósofo, teólogo, astrónomo y médico, su capacidad intelectual abarcaba todas las ramas del saber humano.

El Rambam se convirtió en la máxima autoridad rabínica del mundo judío. Su extraordinaria síntesis de toda la legislación talmúdica en Mishne Torá o Yad Hajazaká (= Segunda Ley o La Mano Fuerte), sigue siendo obra de consulta para los jueces judíos. 
Su tratado Moré Nevujim (Guía de los Perplejos), escrita en árabe y casi al mismo tiempo traducida al hebreo y al latin, es la obra cumbre de la filosofia judia medieval, en la que se trata de sintetizar la fe religiosa y la filosofia aristotélica. Todos los fenómenos y los aspectos de la naturaleza y de la vida, del pensamiento y de la acción, fueron para él parte de una totalidad armónica.

No en vano es tradicionalmente conocida entre los estudiosos judíos, la frase: "Desde Moisés (el gran Líder bíblico) hasta Moisés (Ben Maimón) no surgió otro como Moisés".

\section{Datos BIOGRÁFICOS}

La ciudad de Córdoba contaba a principios del siglo XII con más de un millón de habitantes, sesenta mil edificios, ochenta colegios, tres universidades y una biblioteca con setecientos mil volúmenes manuscritos. Toda esta infraestructura urbana y cultural fue un factor fundamental que le permitió a esa ciudad llegar al máximo esplendor intelectual de la época.

El alto nivel cultural del centro espiritual judío en Córdoba, era a la vez paralelo al de la ciudad.

El juez rabínico Rabí Maimón Hadaián (= el Juez), padre de Maimónides, pertenecía a una familia aristocrática por descender en línea directa del rey David. Tenía un gran conocimiento del Talmud, así como gran erudición en las ciencias de la época, principalmente en la Astronomía.

Rabí Maimón "el Daián" escribió un Comentario sobre la Torá, algunos de cuyos fragmentos fueron puestos al alcance del público por la publicación trimestral en inglés Jewish Quarterly Review (JQR). Asimismo, compuso comentarios para el Talmud y diversos libros sobre Halajá.

En su Introducción al Comentario de la Mishná, Rambam escribió: "He recogido todo lo que llegaba a mis manos de los comentarios de mi padre y maestro, bendita sea su memoria".

Según la tradición, Rabí Maimón Hadaián fue sepultado en la ciudad sagrada de Jerusalén. Aparentemente, desde que llegara a ella en el año hebreo 4925 (=1105 de la e.c.), no salió de Israel a causa de su edad avanzada. Según otro testimonio, falleció y fue sepultado en Egipto. La opinión actualmente aceptada es que Rabí Maimón está sepultado en la ciudad de Tveria (= Tiberiades), junto a su hijo Rambam. Sobre la lápida original decía: "Aquí yace Rabi Maimón el Daián, "personalidad selecta'".

Poco se sabe sobre la madre de Maimónides, solo que no alcanzó a criar a su hijo Moisés pues tuvo una complicación en el parto y murió.

En el año hebreo 4895, el 30 de marzo de 1135, nace en la Aljama de Córdoba Moisés Ben Maimón. En Occidente se le conocerá como Maimónides, el gran médico y filósofo judío; para los judios, es conocido como el RaMBaM, acrónimo que corresponde a: Rabi Moisés Ben Maimón. 
De la familia de Maimónides se sabe que su hermano David se desempeñaba como comerciante en joyas y su hermana Shulamit era una excelente caligrafa, que fue de gran ayuda para la redacción de sus escritos.

La personalidad que impresionó a Rambam desde su infancia fue Rabí Yosef Haleví Ibn Migash, quien fuera el maestro de su padre, Rabí Maimón el Daián. Rambam afirmaba que Rabí Yosef era "asombrosamente sabio" en el estudio del Talmud.

Los historiadores relatan que el mismo Rabí Yosef profetizó al Rambam un futuro esplendoroso, "a cuya luz los hijos de Israel irían desde la salida del sol hasta el ocaso". Ciertamente, esta profecía se cumplió en gran medida.

Rambam tuvo el privilegio de que lo precedieran grandes personalidades y estudiosos de la Torá, autores de una vasta creación en el área del Piut (poesía lítúrgica), la poesía, el pensamiento filosófico y la Halajá. Este contexto se desarrolló en la Edad de Oro que caracterizó la vida judía bajo el dominio del Islam ilustrado en España, y que llegó a su fin con el ascenso de los almohades fanáticos en el año 1148 .

Debido a la gran atención por parte del Rabí Maimón a su hijo, Maimónides no solo se limitó al estudio judaico, sino que dominó a su corta edad las matemáticas, astronomía, filosofia $\mathrm{y}$ fisica.

Rambam creció y se educó hasta llegar a los trece años, en un ambiente de tranquilidad y bienestar.

En 1148, el sur de España es conquistado por los almohades, una secta fanática del Corán que obliga a emigrar a los judíos y cristianos a menos que se conviertan a la fe de Mahoma o decidan morir por sus creencias.

En ese año la familia de Rambam se vio forzada a migrar, durante once años, de ciudad en ciudad en España, tomando la precaución de no pasar a la zona cristiana de la Península lbérica. Preferían sufrir necesidades a condición de no trasladarse a un lugar afectado por la fe idólatra del cristianismo. Cuando Rambam llegó a los trece años, su familia abandonó Córdoba y se trasladó en 1151 a la ciudad costera de Almería, en el sur de España. A los veintiún años, su familia se trasladó a Fez, capital de Marruecos, sede del reino de los almohades.

La razón que los impulsó a abandonar España fue la conquista de Almería por los almohades. Esta secta fanática obligaba a los judios a convertirse al Islam, hecho que provocó una emigración masiva de judíos, entre ellos la familia de Rambam.

El hermano de Rambam, David, era el sustento de la familia y se dedicaba al comercio de perlas y piedras preciosas, hecho que aumentaba su prestigio, y también por la tolerancia del sultán almohade hacia sus súbditos. Los judios que vivian en la capital del reino convirtieron a la familia de Rambam en personas bien vistas en la ciudad de Fez. 
La situación de los judios era sumamente mala, a excepción de algunos sabios de la Torá. La mayor parte de los judios se había convertido al islam, y habia anusim (marranos) que conservaban su religión en secreto. Los judios estaban obligados a oír los sermones de los predicadores en las mezquitas.

Aprovechó esos años para seguir estudiando la Torá y redactando sus escritos. En cada ciudad a la que llegaban, Rambam tomaba contacto con los sabios de la Torá y estudiaba con ellos. Asimismo, se perfeccionó en el estudio de las ciencias y la filosofía.

Cuando Abu-Visir, a la cabeza de los almohades, volvió a Fez de sus conquistas en España, las normas islámicas se tornaron más severas, lo que llevó al inicio de la huida de los judíos anusim, entre ellos la familia Maimón, que abandonó la ciudad de Fez en 1164.

En dicha ciudad se conserva hasta el presente la casa en la que Rambam se ocultara de los edictos y persecuciones. Uno de los poetas árabes de Fez, llamado Abu el-Arab Misha, atestiguó ante el gobierno que la familia Maimón era musulmana, para salvarlos.

Una vez que abandonaron Fez llegaron a la ciudad de Sebta, en la costa de Marruecos, residieron allí una temporada y posteriormente se embarcaron para un viaje de un mes hasta el puerto de Acco en la tierra de Israel.

En su comentario al Tratado de Rosh Hashaná, Rambam relató que el viaje empezó en la noche del domingo 4 de Yiar. En el camino debieron sortear una tempestad que amenazó con hacerlos naufragar, y el domingo 3 de Siván salieron del mar indemnes.

Rambam visitó Jerusalén y Hebrón el 3 y el 9 de Marheshván del año 4926 (1165). En el curso de su visita prometió que esos dos dias habrian de ser dias propicios para comer y beber, para orar y regocijarse en D's.

"Asi como he tenido el privilegio de orar en ella en su destrucción, yo y todos los hijos de Israel habremos de ver su consuelo a la brevedad, amén".

En aquellos tiempos, en Eretz Israel tuvieron lugar las Cruzadas, que causaron estragos entre los judios. La residencia en Eretz Israel se habia vuelto algo sumamente peligroso, lo que obligó al Rambam a emigrar a Egipto. Allí, Rambam se convirtió en médico del sultán Saladino en El Cairo, teniendo gran influencia en el palacio real. Cuando Saladino conquistó Jerusalén, permitió a los judios volver a establecerse en ella, a pedido de Rambam.

Los judios de Egipto aprendieron a conocer y valorar a Rambam durante su estadía en el país. Después de su muerte, la admiración por él fue en aumento, razón por la cual sus descendientes fueron designados neguidim (ministros consejeros) de los gobernantes.

Los neguidim juzgaban a los judios en temas civiles y económicos, y sus nombres fíguraban en las diversas clases de documentos. Asimismo, eran los representantes oficiales de la comunidad judia frente al gobierno gentil. 
La estirpe de neguidim descendientes de Rambam se inició en el año 1228, cuando su hijo Rabí Abraham asumió el cargo, y se prolongó hasta 1355, año en que la descendencia llegó a su fin.

\section{LOS ESCRITOS DEL RAMBAM}

Maimónides comenzó su labor como comentarista de la Torá y como maestro de las generaciones venideras, cuando ya a los veinte años de edad empezó a escribir su Comentario a la Mishná.

Rambam sentía la necesidad de difundir esta obra, ya que el mundo judio se encontraba en crisis debido a los diversos edictos, la reducción del número de estudiosos y el incremento de versiones de la Torá Shebeal Pe (la Tradición Oral). Los peligros que acechaban a la continuidad espiritual y religiosa del judaísmo eran similares a los de la época de Rabí Yehudá Hanasí, compilador de la Ley Oral en el siglo III de la era común. Como es sabido, Rabí Yehudá temía que los judíos olvidaran la Torá Shebeal Pe a raíz de los numerosos problemas de la supervivencia cotidiana de los judios y los diversos exilios.

Rabí Yehudá Hanasí se basó en el versículo de Tehilim (Salmos): "Es tiempo de que obre D's, porque ellos han anulado Tu Ley", es decir, se puede violar un precepto, la prohibición de poner la Torá Shebeal Pe por escrito, para salvar en nombre de D's toda la Torá y la fe.

Los Sedarim con los cuales Rambam empezó su comentario de las mishnaiot son: Moed, Nashim, Nezikin y Maséjet Hulin de Séder Kdoshim. (La Mishná incluye seis Sedarim, que son los siguientes: Zraim, Moed, Nashim, Nezikin, Kedoshim y Taharot).

A los veintitrés años, una vez finalizada la redacción de Maamar Haibur ("Tratado sobre el calendario"), escribió y difundió Hiljot Ha-Yerushalmi.

La perseverancia y el poder de concentración con los que Rambam se había visto agraciado, además de sus múltiples virtudes y su genialidad, lo convirtieron en una fuente inagotable que se expresaba de manera exhaustiva, condensada y precisa. Estas características le fueron de gran ayuda en su obra monumental Mishne Torá, que compuso durante doce años, en los que permaneció encerrado en su casa, totalmente dedicado a su trabajo.

Esta obra que incluye mil capítulos de jurisprudencia, Rambam empezó a escribirla a los treinta y tres años de edad y la terminó a los cuarenta y cinco, en la primera mitad de su estadía en Egipto.

En aquellos tiempos, Rambam no debia ocuparse de la subsistencia porque su hermano David se dedicaba al comercio de perlas y piedras preciosas, que permitia a la familia Maimón una vida acomodada. Era una clase de cooperación similar a la de las tribus de Isajar y Zevulún, sobre quienes está escrito en la Torá: "Alégrate, Zevulún, de tus correrías por el mar; pero tú, Isajar, regocijate en tus tiendas" (Libro Devarim, Parashat "Vezot haBerajá"). 
En su introducción a Mishné Torá, Rambam señaló que su intención era la de facilitar el estudio y acortar la senda hacia el conocimiento de toda la Halajá. Citando sus palabras: "Porque la persona lee primero la Torá Shebijtav; después lee esta obra y a partir de ello sabe toda la Torá Shebeal Pe..."

Los críticos del Rambam sostenían que se habia atribuido una libertad absoluta como "juez único" en los dictámenes sobre la Halajá, sin hacer participar en ellos a otros sabios de diversas épocas, y sin señalar al menos las fuentes en las que basaba sus dictámenes.

Sus discípulos se dedicaron a buscar explicaciones para tender un puente entre la filosofia y las enseñanzas de la Torá, a fin de justificar el enfoque de su maestro.

Su deseo no se cumplió, pues a lo largo del tiempo se escribieron decenas de libros de estudio, crítica y revelación de las fuentes de Misnhné Torá, también conocido como Hayad Hajazaká.

En tiempos de Rambam vivió en Francia el sabio Rabi Abraham Ben David de Posquières conocido como Rabad, quien fue el polemista más acérrimo de los textos de Rambam, en especial sobre el famoso tratado filosófico Moré Nevujim y Hayad Hajazaká. Rabad era una persona mayor, un hombre sumamente rico y conocedor del Talmud, un gran estudioso que abarcaba numerosos ámbitos del saber.

En el testamento a su hijo, Rambam escribió recurriendo a las palabras dichas en su momento por Rabi Akiva: "Nunca me ha derrotado nadie, sino quien poseía un solo oficio", es decir, la critica de Rabad no me parece seria porque se dedica a muchos temas y no profundiza en ninguno en especial. Por eso no hay un "aficionado" que pueda derrotar a un "experto".

Los estudiosos trataron de minimizar la critica de Rabad, porque confiaban en la grandeza de Rambam. Hubo quienes vieron esa crítica virulenta como una consecuencia de su inmensa riqueza y edad avanzada, tal como señala el versículo de Mishlei (Proverbios): "Pero el rico contesta ásperamente". A pesar de ello, Rabad fue considerado uno de los grandes sabios de su época.

Rambam escribió la Epistola sobre la Resurrección de los Muertos en 1191, como explicación y disculpa, para tranquilizar a sus amigos ingenuos y hacer a un lado a quienes sospechaban de él con inocencia, alevosía, o tal vez por incomprensión, con respecto al principio de fe respecto a la "resurrección de los muertos".

Como Rambam fue muy sucinto en su definición y explicación de la resurrección de los muertos y no se explayó sobre ella, tal como lo había hecho con otros principios o con respecto al mundo por venir, quienes no lo entendían sostenian que la creencia en la resurrección de los muertos era endeble en él, y por eso lo mencionaba casualmente y con un lenguaje débil. Le pedían que explicara su opinión al respecto con más claridad, para que todos conocieran este tema crucial con más precisión.

Hasta la época de Rambam, la creencia en la "permanencia del alma" y en la "vida en el mundo por venir" estaba estrechamente relacionada con la fe en la resurrección de los muertos, 
es decir, un mundo por venir totalmente bueno y plácido que empezaría con el despertar de los enterrados que dormían el sueño de la muerte; la resurrección de los muertos guardaba relación con el inicio de una nueva vida a la llegada del Mesias hijo de David. El Mesías llegaría, vería las maravillas y haria resucitar a los muertos; en ese momento empezaría la vida en el mundo por venir, una era en la que todo habría de ser bueno.

Según la doctrina de Rambam, hay una diferencia entre la "vida en el mundo por venir", que es la vida de las almas, y la vida en el mundo de la resurrección, que es la vida del cuerpo. Para Rambam, la resurrección de los muertos no se relaciona precisamente con la llegada del Mesías y las maravillas que producirá; el Mesías no tendrá que revivir a los muertos, sino que la resurrección de los muertos y su momento dependen de la voluntad del Creador: a Su voluntad la apresurará y a Su voluntad la demorará, y ella habrá de producirse cuando sea Su voluntad.

Durante mucho tiempo, los judios estuvieron sometidos a edictos de conversión forzosa, y los anusim perdieron la paciencia. "El hábito se torna naturaleza", y la fe judia empezó a debilitarse entre la masa de anusim, que lenta y gradualmente se habituaron a su nueva vida.

Al tomar conocimiento de la atmósfera de depresión que cundía entre los judíos, Rabí Maimón, el padre de Rambam, decidió hacerle frente: identificarse con los amusim e insuflarles seguridad y esperanza en tiempos mejores. Por eso escribió la Epístola de Consolación, para consolar a esas almas doloridas por los males del exilio, que lamentaban la lejanía de la salvación.

En la Epístola de Consolación, Rabí Maimón, el padre de Rambam, se nos revela como una persona inflamada de un amor sagrado e inocente por su pueblo y su D's. Ése fue el mensaje de amor que legó a su hijo "Rabenu Moshé", el Rambam.

Después de haber sido reconocido como el más grande pensador de su tiempo, Rambam expresó sus opiniones sobre diversos temas. Solía responder a las numerosas preguntas que se le planteaban por medio de epistolas (cartas) que enviaba a distintos lugares del mundo.

Rambam autorizó la enseñanza de la Torá a los cristianos, y debe verse en ello una bendición, pues tal vez eso los acerque a la verdadera fe.

En su epístola a los judíos en Francia, rechazó rotundamente la dedicación a la astrología y también a la hechicería. Rambam expresó esta opinión en diversos lugares en sus escritos.

Los caraítas, que solo reconocían la Torá Shebijtav y se negaban a creer en la Torá Shebeal $\mathrm{Pe}$, vivían en el seno de la diáspora judía en Egipto. Cuando Saladino ocupó el gobierno, un caraita llamado Zuta logró ser designado naguid de los judíos. Rambam trató de destituirlo y aprovechó su cercanía a la casa real en su carácter de médico de la corte para lograr su objetivo.

Rambam esperaba y exigía acercar a los caraitas de su tiempo, porque los consideraba como niños perdidos y confiaba en que sus hijos se aproximaran más a la fe. Ciertamente, Rambam tenía razón en su evaluación, y un tiempo después muchos caraítas aceptaron la Torá Shebeal Pe que en un principio rechazaban. 
En el curso de sus numerosos viajes, Rambam resolvió abandonar Eretz Israel para radicarse en Egipto, después de una permanencia de seis meses en Yafo.

Eretz Israel estaba dominada en ese entonces por los cruzados, que expulsaron a los judíos a Egipto. A pesar de las persecuciones, Rambam prefirió vivir bajo dominio islámico y no bajo dominio cristiano, considerado como idolatria. El hecho de que era un médico afamado y un gran comerciante en perlas y piedras preciosas le permitió sobrevivir en un país dominado por el islam.

La segunda epístola escrita por Rambam, titulada Epistola a Teimán (el Yemen), fue redactada durante su estadía en El Cairo, capital de Egipto. La Epistola de la Conversión Forzosa fue escrita cuando aún se encontraba en Fez, capital del Magreb.

La primera epístola fue escrita por Rambam espontáneamente, sin que se le requiriera, por un despertar interior que ya en su juventud lo habia impulsado a compartir el yugo de sus hermanos. En cambio, la segunda epístola fue escrita cuando ya era mundialmente famoso, como respuesta a quienes se dirigían a él en su aflicción, para pedirle consejo y apoyo.

El objetivo de estas dos epístolas consistía en "fortalecer las manos débiles y reanimar las rodillas que flaqueaban".

La redacción y envio de la Epístola a Teimán constituía un peligro para Rambam, porque en ella criticaba a la fe islámica y a su fundador Mahoma, por una parte, y por la otra, alababa a la fe judia como la fe verdadera.

Asimismo, el hecho de que la epístola hubiera sido escrita en árabe podía fácilmente convertirse en motivo de acusación en su contra. Ciertamente, en ella exhortaba a los judíos del Yemen a que no la difundieran, para que no cayera en manos de intrigantes malintencionados.

Rambam escribió: "La razón de la mayoria es algo que no debe inspirar miedo ante el peligro".

Rambarn actuó en la corte real en El Cairo para designar al hermano del sultán Saladino como gobernador del Yemen. De esa manera logró revocar las persecuciones y los edictos de conversión forzosa.

Durante muchos años, los judios del Yemen se comportaron de acuerdo exclusivamente con los dictámenes de Rambam. Asimismo, en el Kadish añadieron una plegaria en su honor: "En vuestra vida y en vuestros días, y en vida de Rabenu Moshé Ben Maimón".

Aproximadamente un año después de que Rambam escribiera la Epístola de la Conversión Forzosa (Igueret Hashmad), se produjo un acontecimiento muy significativo en su vida: su hermano David se ahogó en el mar cerca de la India, en un viaje de negocios. 
El hermano comerciaba con el dinero de la herencia familiar, y Rambam recibia los dividendos. A partir de la muerte de su hermano se vio forzado a ganar el sustento de sí mismo, de su familia, de su cuñada viuda y de la familia de ésta última.

A partir de este acontecimiento trágico, Rambam empezó a dedicarse a la medicina.

En su Epistola a Rabí Yosef BeRabí Yehudá del año 4952, Rambam escribió: "Deseo informarle que he alcanzado gran fama en la profesión médica entre los más grandes reyes... Esto me ha llevado a consumir mis dias en El Cairo visitando enfermos..."

La muerte de su hermano David y la pérdida del caudal de perlas y piedras preciosas, y posteriormente su fatigosa dedicación a la medicina. En sus palabras: "Paso la mayor parte del día en cama, con el yugo de los goim al cuello ocupado con la medicina, lo que ha debilitado mis fuerzas y no me deja ni una hora del día o de la noche".

En su Epistola a Rabí Shmuel Ibn Tibón (traductor de su libro filosófico Moré Nevujim) escribió, entre otras cosas: "Finalmente, ningún judio podrá estar conmigo a solas, salvo en Shabat. Ese dia acude toda la grey, o su mayoría, después de la plegaria, y conduciré a la congregación en sus quehaceres semanales..."

Cuando Rambam vivía en Egipto, su amigo árabe Abu el-Arab Misha lo delató, diciendo que Rambam insultaba y agraviaba al islam. ¿Por qué razón lo hizo, si cuando ambos vivían en Fez, el poeta había atestiguado a su favor y lo había salvado de la muerte? Cuando el poeta vio el éxito de Rambam en Egipto, sintió envidia y presentó una demanda jurídica en su contra en El Cairo.

Para fortuna de Rambam, en el juicio debió comparecer ante un magistrado ilustrado y amante de las ciencias, que dictaminó que en el caso de una fe impuesta por la fuerza, el hereje no es considerado traidor. Así fue como Rambam resultó exculpado y quedó en libertad.

Rambam dejó numerosos escritos en el área de las ciencias médicas que se conservaron hasta nuestros días y que siguen siendo cuidadosamente revisados y traducidos.

Maimónides contrajo matrimonio dos veces, de su segundo matrimonio nació un hijo llamado Abraham, que llegó a ser un gran erudito y dirigente espiritual del judaísmo egipcio.

La vida creadora y prolifica consagrada a la sabiduría y al pueblo judío, se truncó a la temprana edad de 69 años, el 2 de Tevet del año 4965 (13 de diciembre de 1204). Los sabios solían decir: "Quien reside en Eretz Israel, sus pecados son perdonados... Y quien es sepultado en ella, se le perdona todo y es como si el lugar en que se encuentra fuera un altar de expiación, tal como dice: $Y$ hará la expiación de su tierra y de su pueblo".

Los restos del Rambam fueron trasladados a la ciudad de Tiberíades en la tierra de Israel. 


\section{MAIMÓNIDES, EL MÉDICO}

\section{El LEGADO MÉDICO DE MAIMÓNIDES}

Es poco lo que se conoce sobre la juventud y la educación médica de Maimónides. No hay fuentes que indiquen que tuviera una educación médica formal. En sus aforismos médicos menciona a "los mayores de antes quienes yo he leído", siendo esta la única alusión a algún estudio autodidacta de medicina.

Unas pocas veces menciona a Ibn Sur quien escuchó enseñanzas de su ilustre padre (el gran médico Abu Marwan lbn Zuhr) a quien Maimónides tenía en gran estima. Maimónides debe haber sido un ávido lector, ya que sus escritos médicos evidencian un profundo conocimiento de los antiguos autores griegos en traducción árabe y de trabajos médicos musulmanes. Hipócrates, Galeno y Aristóteles eran sus inspiraciones griegas, Rhazes de Persia, Al Farabi, e Ibn Sur los médicos hispanoarábigos, son los autores musulmanes más frecuentemente citados por Maimónides.

En realidad, Maimónides se volcó a la medicina como un medio de subsistencia después de la muerte de su padre en 1166 y la de su hermano en un naufragio, poco tiempo después. Maimónides quedó a cargo de la esposa de su hermano y sus niños.

Después de la muerte de su padre y tras un año de enfermedades, inició la práctica de la medicina. En 1174, a los treinta y nueve años fue nombrado médico de la corte del Vizir Al Fadhil, regente de Egipto durante la ausencia del sultán, Saladino el Grande, quien peleaba en las cruzadas en Palestina. Asimismo se cuenta que Ricardo Corazón de León, quien también luchaba en las cruzadas, invitó a Maimónides a ser su médico personal, oferta que Maimónides rechazó.

Su reputación como médico creció en Egipto y países vecinos y su fama como teólogo y filósofo se hizo mundial.

En 1113 murió Saladino, y su hijo mayor Al Mdal Nur ad Din Ali lo sucedió.

Los deberes médicos de Maimónides se hicieron todavía más pesados, como lo describe en la famosa carta que escribió a su amigo, discípulo y traductor, el Rabino Samuel Ibn Tibbon, en el año 1199:

"Vivo en Fostat y el sultán en Cairo; estos dos lugares están uno del otro a una distancia de dos límites de Shabat (áreas delimitadas alrededor de un pueblo dentro del cual está permitido trasladarse en Shabat, aproximadamente una milla y media). Mis deberes para con el sultán son muy pesados. Estoy obligado a visitarlo todos los días de mañana y cuando él o alguno de sus niños o concubinas no se sienten bien, no puedo abandonar Cairo y debo permanecer la mayor parte del dia dentro del palacio. También sucede que uno o dos de sus funcionarios caen enfermos y yo debo atender su curación. Asi en general todos los días muy de mañana voy al Cairo y aun cuando nada fuera de lo común sucediera alli, no regreso a Fostat sino hasta la tarde. Entonces estoy hambriento y me encuentro con que la antesala de mi casa esta llena de personas, tanto judíos como gentiles, nobles y plebeyos, jueces y policias 
comunes, amigos y enemigos. Una multitud mixta que espera el momento de mi regreso. Desciendo de mi animal, lavo mis manos, prosigo a mis pacientes y los invito a esperarme mientras pruebo algún refrigerio liviano, la única comida que como en 24 horas. Entonces voy a atender a mis pacientes y escribo prescripciones e instrucciones para sus dolencias. Los pacientes entran y salen hasta el anochecer y a veces, te lo aseguro, hasta dos horas o más en la noche. Converso con ellos y aun les prescribo cuando estoy acostado por el agotamiento. Cuando cae la noche estoy tan cansado que apenas puedo hablar.

Como consecuencia de esto, ningún judio puede conversar conmigo o trabar amistad con excepción del Shabat. Ese día la congregación entera o por lo menos la mayoria, viene a mí después del servicio de la mañana, cuando les instruyo acerca del modo de proceder durante la semana entera (Maimónides era también el lider espiritual de la comunidad judía de Egipto).

Estudiamos juntos hasta el mediodía, cuando se van. Algunos de ellos vuelen a estudiar conmigo después del servicio de la tarde hasta el rezo de la noche. De esta manera paso los dias. Solo te he contado aquí una parte de lo que verías si me visitaras".

Su aporte profesional a la práctica de las ciencias médicas es de gran importancia y en muchas áreas fue un pionero de la investigación.

Maimónides clasificó la medicina en tres divisiones: la preventiva, la curativa y la que atendía a los convalecientes, incluyendo los inválidos y los ancianos.

Su enseñanza médica, basada en la entonces patología humoral de Hipócrates y Galeno, era de estricto carácter racional.

Combatió duramente el uso de los hechizos, encantamientos y amuletos en el tratamiento de enfermos y desaprobaba toda fe ciega en la autoridad.

Estimulaba a sus discipulos a observar y razonar criticamente. Un ejemplo es el siguiente extracto de sus Aforismos, donde dice:

"Si alguien te afirma que tiene prueba por su propia experiencia de algo que necesita para confirmar su teoría, aún cuando sea una persona de gran autoridad, seriedad y moralidad, deberás dudar. No dejes tu mente ser arrastrada por las novedades que te cuenta sino que examina cuidadosamente sus teorías y sus creencias asi como debes hacer respeto a las cosas que declara haber visto; examina el asunto sin dejarte de persuadir fácilmente. $Y$ esto que te digo es cierto, sea que la persona en cuestión fuera un notable o uno del pueblo. Porque una voluntad fuerte puede llevar a una persona a hablar erróneamente, especialmente durante una discusión..."

En opinión de Rambam, el médico necesita tres cosas:

1. Lógica (conocimientos)

2. Arte (pericia profesional)

3. Intuición (amor a la profesión). 
Para ser una persona fisicamente sana, se debe cuidar también el equilibrio emocional. El médico debe saber que la persona realmente sana tiene también buen ánimo, y que los enfermos se deprimen. El fortalecimiento del cuerpo para lograr la tecuperación solo puede alcanzarse fortaleciendo y perfeccionando los aspectos morales, a través de la lectura de libros sobre temas éticos, los libros de los profetas o de los filósofos, y la regulación de la vida cotidiana de acuerdo con sus enseñanzas.

Las normas para preservar la auténtica "paz del espíritu" incluyen la voluntad de aceptar todas las imposiciones de la vida, tanto las buenas como las malas. Esto se logra por medio de la placidez del ánimo, el sosiego y el agradecimiento al Creador del mundo, tal como lo exigen los sabios de todas las religiones elevadas. No todos los acontecimientos que las masas consideran como buenos o malos, se revelan con el correr del tiempo como tales.

Rambam se revela no solo como médico, sabio y estudioso, sino también como el clásico médico de almas que alivia y reconforta a las personas fatigadas que acuden a él y se ocupa de sus enfermedades con abnegación y fe. Inclusive el sultán al-Afazel le solicitó ayuda, porque conocía su grandeza en el área de la medicina.

La grandeza de Rambam en su desempeño como médico en la corte real se pone de manifiesto en el hecho de que, a pesar del inmenso respeto que sentía por el sultán al que prestaba sus servicios profesionales, no se abstuvo de condenarlo indirectamente por su estilo de vida disipado, el derramamiento de sangre, y sus deseos desbordados. Para estar fisicamente sano, el individuo debe preocuparse también por el equilibrio espiritual. El médico debe saber que las personas realmente sanas tienen también buen ánimo, y que los enfermos se deprimen.

La meta del médico consiste en devolver la salud a los enfermos, o al menos llevarlos a una situación cercana a ella. En el pasado, la medicina se basaba mayormente en la especulación, y estaba muy lejos de asentarse sobre conocimientos certeros.

En opinión de Rambam, la salud consiste en lograr que el organismo regule sus perturbaciones, en permitirle constantemente al individuo ejercer su comportamiento habitual y en brindarle la posibilidad de desarrollarse y de concretar su esencia.

La enfermedad consiste en una modificación en alguna parte del organismo que produce alteraciones en el curso habitual, en irregularidades y perturbaciones en la regulación del organismo que permite a la persona cumplir con las misiones que el medio externo le impone. Existen sintomas de enfermedad cuando los estímulos habituales pueden producir reacciones catastróficas; es decir, la enfermedad no es una desviación de la norma, sino una proporción irregular.

En opinión de Rambam, el individuo solo debe comer de acuerdo con las necesidades de su cuerpo, y preservar la salud del mismo para poder dedicarse a los estudios.

Para conservar la buena salud durante largo tiempo, se debe hacer ejercicios físicos todos los días. 
Los cambios extremos en las condiciones climáticas afectan la salud; un clima templado y moderado influye positivamente sobre la salud.

En opinión de Rambam, no se deben cometer excesos en la comida y la bebida, ni acciones disipadas ni llegar a la embriaguez.

La gula y la glotoneria afectan el metabolismo, y eso perjudica la salud.

La persona debe sentarse a la mesa, comer lentamente y dejar algo de comida en el plato.

Cada criatura tiene un alma propia y peculiar. El alma humana no debe ocuparse permanentemente de problemas graves, para no llegar a una situación de desequilibrio. El alma se parece al cuerpo, que necesita descanso después de un trabajo agotador.

En opinión de Rambam, el cuidado del alma y su actividad adecuada constituyen el fundamento para conocer a D's y alcanzar la comprensión de la verdad. La "investigación del alma" es la base de cualquier doctrina moral. La profundización en el alma es el motivo central de sus textos.

Para sanar el alma se debe conocer a fondo sus partes, y cómo están construidas.

Rambam divide al alma en tres partes generales:

a. El alma común a todas las criaturas vivas: el espíritu vital

b. El alma específica del ser humano: su espíritu y raciocinio

c. El alma abstracta: el alma del individuo.

Teniendo en cuenta el lapso transcurrido desde que Rambam desarrollara sus innovaciones médicas, muchos se preguntan si sus textos de medicina siguen teniendo vigencia. Lo que está claro es que aquellos medicamentos han envejecido y no tienen ya la misma importancia que los más eficaces de nuestro tiempo.

Las afirmaciones de Rambam con respecto a la medicina preventiva, la salud pública y la preservación de la salud mental no han perdido valor hasta nuestros días.

Con justa razón, desde el punto de vista médico nuestra época se define como "la era de la medicina preventiva". La misma ha logrado prolongar el promedio de vida de cuarenta años en 1850 a setenta años en 1960 , en particular, gracias a la higiene pública, los sistemas cloacales, el agua corriente, la cirugía en condiciones de esterilización, etc.

En sus principios sobre medicina preventiva, Rambam nos enseña la importancia de la higiene pública y privada, el cuidado de la salud física y mental. Asimismo, enfatiza la importancia de la medicina preventiva y de la higiene mental como fundamentos del cuidado de la salud individual y colectiva. En sus comentarios a la Mishná y en Mishné Torá, Rambam escribió sobre estos 
temas por razones religiosas y filosóficas, $y$ en la literatura médica lo hizo por razones puramente profesionales. Rambam enfatiza reiteradamente que la preservación de la salud y la sanidad tiene mucha más importancia que el tratamiento médico con medicamentos.

Rambam exige que, en caso de necesidad de atención médica, el médico no limite su atención a determinado miembro u órgano enfermo o afectado, sino que preste atención a todo el cuerpo y el alma del enfermo a un mismo tiempo.

La piel de todo el cuerpo es un órgano sumamente sensible y delicado, que refleja las sensaciones del alma, tal como un barómetro mide la presión ambiental.

El rubor y la palidez, el calor o el frío de la piel brindan testimonio de determinados movimientos del corazón y del sistema circulatorio, que cambian incesantemente y se relacionan con el aparato respiratorio.

La lengua depende de la voluntad del individuo y puede revelar los estados de ánimo u ocultarlos, por ejemplo: decir mentiras y falacias. Pero los labios, con el temblor o la sonrisa, constituyen un idioma claro y sincero.

Determinadas enfermedades fisicas pueden curarse total o parcialmente, a través de la psicoterapia.

Las enfermedades que pueden curarse a través de la psicoterapia son las contracciones, el estreñimiento, contracciones en la vesícula, el estómago y el esófago, asma bronquial, alta presión, retención de orina.

El miedo, la depresión o el shock anímico afectan a una persona en el corazón o el sistema circulatorio, mientras que a otra le alteran la regulación de los minerales y las hormonas; en una tercera perjudican el estómago, etc.

En opinión de Rambam, un ataque de pánico, depresión o shock anímico afectan a distintas personas de diferentes maneras. Por ello, hay que tomar en cuenta la historia personal del individuo, su medio ambiente, su educación, las enfermedades que padeció en la infancia, etc., que producen mayor sensibilidad en un órgano u otro.

Las opiniones, ideas y conclusiones de Rambam en medicina y ciencias naturales recibieron influencias de la filosofia greco-árabe y de la religión judia. No obstante, se percibe en ellas una posición independiente y original, típica de Rambam. Ellas nos muestran su amplia experiencia, así como las ideas usualmente aplicadas por la medicina de su tiempo.

Rambam exigía al médico un elevado conocimiento profesional; la atención individual del enfermo después de una honda reflexión; el uso de todas las fuerzas médicas que pudieran revivir y alentar el alma enferma, responsable de la fuerza vital del cuerpo. Por eso, el médico debía ser médico de almas, sabio, pensador, conocedor del cuerpo humano y su funcionamiento, sus cambios y las formas de sanarlo. 
Uno de los libros médicos de Rambam, titulado Explicación de los nombres de las enfermedades, analiza cuatrocientos cincuenta medicamentos con nombres parecidos en idiomas diferentes. Rambam no incluyó en él los medicamentos que tenían un solo nombre, porque no daban lugar a confusiones, salvo aquellos casos en los que temía que los médicos se equivocaran y perjudicaran a los enfermos.

Rambam no señaló los nombres de los medicamentos en hebreo, porque en su época los medicamentos no se comercializaban con nombres hebreos.

En la mirada del enfermo se puede leer el pedido que surge de lo más hondo de su corazón: "Ayúdeme en mi pesar y en mi aflicción, confio en usted, creo en usted como emisario del Creador del mundo, deposito en sus manos mi cuerpo y mi espíritu".

Las habilidades que debe tener un médico para conquistar la confianza del enfermo son: conocimientos profundos en humanidades y ciencias naturales que refuerzan la moral del médico y lo capacitan para ser un auténtico amigo de las personas; profunda conciencia moral y religiosa; gran pericia y destreza profesional; capacidad de profundizar en el corazón del enfermo y percibir sus dolores y pesares; percepción de las relaciones espirituales y corporales del enfermo; poder de influencia y autoconfianza que irradien autoridad; asimismo, el médico debe esforzarse siempre por desarrollar su personalidad.

En la hipnosis, el cuerpo se libera del exceso de tensiones a las que está sometido y el alma, del imperio de la razón consciente.

La liberación del cuerpo de las tensiones excesivas conduce a una situación de "equilibrio espiritual" y "placidez" en el pleno sentido de la palabra.

La hipnosis aleja al enfermo de todos los pensamientos lógicos y de la crítica racional, por una parte, y de la tensión de la vigilia, por la otra. Ofrece a la persona un desahogo, le infunde la energía y los bríos que nacen de sus fuerzas espirituales internas, lo lleva a la "moderación" y la felicidad suprema y lo aparta del egoísmo, elimina el "yo" particular y lo acerca al "nosotros", a una situación de amparo y de confianza en D's y en sus acciones.

La actividad fisica es un gran principio para preservar la salud y prevenir la mayor parte de las enfermedades. Esto es lo que afirma Rambam en su libro El cuidado de la salud.

La actividad física incrementa el calor del cuerpo, elimina las toxinas y acelera la respiración. Pero se debe evitar una actividad fisica exagerada que incrementa el ritmo respiratorio, lo que no es bueno para la mayor parte de la gente. Se debe realizar actividades fisicas antes de las comidas y no después de ellas.

La persona solo debe comer después de sentir hambre justificada (es decir, verdadera). La persona solo debe beber agua después de sentir sed justificada (es decir, verdadera). Asimismo, es preferible beber después de la comida. 
En el comienzo de El cuidado de la salud, Rambam detalla varias indicaciones prácticas para preservar la salud, apropiadas para cualquier persona y fáciles de recordar.

No comer hasta hartarse, sino hasta sentirse tres cuartas partes satisfecho.

La actividad fisica es beneficiosa antes de las comidas, pero no después de ellas. No hacer actividad fisica en exceso.

La gran variedad de alimentos diferentes es perjudicial, porque despierta el apetito más que lo deseable.

"Si el hombre se comportara consigo mismo como con la bestia sobre la que monta, evitaría muchas enfermedades". La explicación es la siguiente: el individuo come demasiado, pero da poca comida a su animal; fatiga a su bestia, pero no hace actividades físicas por sí mismo; el animal descansa y duerme como corresponde, pero el individuo no duerme lo suficiente.

El libro El cuidado de la salud de Rambam se divide en cuatro partes:

Primera: El cuidado general de la salud humana.

Segunda: Qué debe hacer el enfermo cuando no hay un médico cerca.

Tercera: Recomendación personal de medicamentos al sultán, de acuerdo con sus enfermedades.

Cuarta: Normas útiles al sultán en su situación, aplicables también a otras personas.

La estructura del libro El cuidado de la salud nos muestra que la concepción de Rambam afirmaba que existen normas médicas que se adecuan a todas las personas por igual. Por otra parte, se debe adaptar a cada enfermo el tratamiento adecuado y específico.

Rambam escribió dieciocho libros de medicina. El motivo que lo impulsó a escribir la mayoría de ellos fueron los pedidos de gobernantes y altos dignatarios, que buscaban alivio a sus enfermedades.

Rambam se anticipó asombrosamente a otros estudiosos en muchas afirmaciones y definiciones médicas. Ya entonces habia escrito sobre temas que se estudian actualmente en medicina.

Podemos destacar por lo menos 10 innovaciones de Rambam en las ciencias médicas:

1. Revocó todas las clases de curanderismo.

2. Exigió un diagnóstico sólidamente basado en la verdad científica y previo al tratamiento.

3. Basó su doctrina en la capacidad de autocura del cuerpo.

4. Abogó por la importancia de la medicina preventiva.

5. Enfatizó la relación y la influencia mutua entre el cuerpo y el alma. 
6. La importancia de la dieta para curar la diabetes.

7. Innovó en el ámbito de los venenos y las mordeduras.

8. Sus textos médicos están exentos de palabras superfluas.

9. Medicina para todos, sin diferencias de clases sociales, origen religioso o sexo.

10. La mayor parte de sus libros médicos son actuales aún en nuestros días.

Dentro de sus principales escritos sobre temas médicos, cabe destacar:

Extractos de Galeno, que es una selección de lo que Maimónides consideraba más relevante de entre los 100 libros escritos por Galeno. Destinada para los estudiantes de la medicina griega.

Comentario sobre los aforismos de Hipócrates, donde el autor polemiza y adopta un punto de vista contrario a la tradición clásica.

Cuando Hipócrates afírma que un "varón nace del ovario derecho, una hembra del izquierdo", Maimónides comenta irónico: "Hay que ser un profeta o un genio para saber esto".

Aforismos médicos de Moisés, es el compendio más grande y contiene 1500 aforismos basados principalmente en la medicina griega. Divididos en 25 capítulos según diferentes áreas de la medicina.

Para citar algunos ejemplos: habla de la apoplejía en la enfermedad cerebro-vascular y del pronóstico, describe el enfisema obstructivo en el capítulo de enfermedades respiratorias, da a conocer con exactitud los signos y síntomas de la neumonía.

Describe ocho signos de la hepatitis: fiebre alta, sed, anorexia, lengua roja que se vuelve negra, vómito biliar, dolor en costado derecho, tos ligera y pesadez en el costado derecho.

Tratado sobre las hemorroides, donde describe las medidas higiénico-dietéticas para su prevención y tratamiento. Está en contra de la sangría o de la cirugía, excepto en los casos severos.

Tratado sobre las relaciones sexuales fue escrito para un sobrino de Saladino que quería aumentar su potencial sexual. Describe alimentos y drogas que actúan como afrodisíacos o como antiafrodisíacos. Aconseja moderación en la actividad sexual y describe la fisiología sexual.

Este Tratado también se titula, el Libro de la Santidad, el cual se divide en tres libros. El primero habla sobre las leyes concernientes a las relaciones ilícitas y describe a la mujer menstruante, la mujer que trae al mundo a un niño, la mujer que sufre el flujo, relaciones entre un israelita y un pagano, bastardos, masculino con partes pudendas mutiladas, descendencia sacerdotal probada o no probada, aspectos generales en el matrimonio y castidad. Trata de ver cada aspecto de la ley en la regulación de la vida íntima e individual, concluyendo con su lección moral: 
"... aleja tu alma de lo que es superfluo, endereza lo que esté torcido, purifica e ilumina cuando esté oscuro... hasta que la virtud brille ante tus ojos con su diurno esplendor".

En el segundo libro trata acerca de los alimentos prohibidos, concemientes a la idea de santidad, mientras que en el escrito tercero cubre todos los aspectos que hablan de la presentación de la carne de los animales permitidos para el consumo humano.

Tratado sobre el asthma, donde explica en 13 capitulos las reglas dietéticas y climáticas apropiadas para los asmáticos. Afirma que el clima egipcio seco es apropiado para esta enfermedad y previene contra el uso de medicamentos poderosos.

También hace recomendaciones útiles para la conservación de la salud y el tratamiento de la enfermedad.

Lo primero que hay que considerar es la provisión de aire fresco, agua limpia y una dieta saludable y describe detalladamente: "El aire de la ciudad está estancado, es túrbio y denso, resultado natural de los grandes edificios, de las calles estrechas, los desechos de sus habitantes... uno debe escoger como residencia un lugar abierto... se debe vivir en un piso superior... con mucho sol... Las letrinas deberán estar lo más lejos posible de las habitaciones de vivienda. El aire puro es la regla más importante para la preservación de la salud del cuerpo y del espiritu".

También afirma que si una persona está alterada emocionalmente o se encuentra en un estado de agitación mental, su bienestar físico sufre y eventualmente puede llegar a enfermar su cuerpo.

Tratado de los venenos y sus antidotos fue empleado como texto de toxicología en toda la Edad Media. Hace recomendaciones para la mordedura de serpiente. También describe el periodo largo de incubación de la rabia y afirma que debe de dejarse abierta la herida por 40 días, así como los síntomas de envenenamiento por belladona y la distinción entre venenos calientes $y$ fríos.

En el Régimen de la salud existe gran variedad de recomendaciones higiénico-dietéticas y del uso de medicamentos, tanto del clima, domicilio, ocupación, baños, actividad sexual, vino, dieta y enfermedades respiratorias.

Según Maimónides, el hombre debe tender a mantener su salud física y su vigor para que su espíritu se mantenga enhiesto, en condición de conocer a D-s, puesto que es imposible entender las ciencias y meditar sobre ellas cuando se está enfermo o hambriento.

\section{MAIMÓNIDES EN LA CORTE DEL SULTÁN. RELATOS TRADICIONALES.}

La sabiduría de Rabí Moshé Ben Maimón no abarca solo Torá, sino también medicina y demás ciencias. Se hizo famoso como médico, en las tierras vecinas. 
El rey de Egipto, Saladino, al escuchar la grandeza de Rambam en el campo de la medicina, lo nombró su médico personal.

Los ministros de la corte tuvieron mucha envidia por la encumbrada posición a la que ascendió Rambam, aumentada por el hecho que éste era judío.

Todas las denuncias y calumnias contadas acerca de su consejero judio fueron rechazadas por el rey.

También los médicos egipcios fueron atacados por la envidia y empezaron a confabular, para demostrar que no eran tan grandes sus conocimientos de medicina.

Ofrecemos a continuación dos interesantes relatos que destacan la gran sabiduría e inteligencia de Maimónides:

VIDA O MUERTE

Todos en la corte del Sultán Saladino de Egipto se pusieron muy contentos cuando nombraron a Maimónides médico personal del sultán. Todos excepto Hakim, él medico árabe que antes habia ocupado ese alto cargo y que por causa del judío había pasado ahora a un segundo lugar.

De aqui en más sería Maimónides quien cuidaría de la salud del sultán y su familia inmediata, mientras que él médico árabe estaría alli para tratar las dolencias de los demás miembros de la casa real y de la corte. Cuanto más celebre era Maimónides, más quedaba en el olvido el médico árabe.

Los sentimientos de envidia y odio hacia su rival, eran cada vez más fuertes y profundos en el corazón de Hakim. Entonces comenzó a tejer un plan con la intención de desacreditar a Maimónides a los ojos del sultán, y de esa forma llevarlo a la ruina.

Un día Hakim se presentó ante el sultán Saladino.

"Su Majestad, he descubierto un plan para envenenar al honorable sultán. Maimónides, su nuevo médico personal es quien planea asesinarle".

El sultán se puso blanco de terror, pero le costaba creer que semejante plan fuera cosa de su fiel médico y amigo judío.

"Si puedes demostrar lo que dices, ordenaré cortar la cabeza a Maimónides. Pero si no puedes probarlo será entonces tu cabeza la que rodará, dijo furioso el sultán".

"Claro que puedo probarlo" respondió el médico árabe "Y así es como lo haré: Todos saben en nuestra profesión que un veneno solo puede ser contrarrestado por un antídoto que es un veneno más poderoso. Le solicito al rey que nos ordene a los dos que preparemos el veneno más 
poderoso posible, de modo que si el rey fuera envenenado en la comida, todo lo que tendrá que hacer es tomar el antídoto y su vida estará a salvo".

"Me parece una idea excelente" dijo el sultán, "pero ¿cómo sabré cuál de los dos venenos es el más fuerte, el tuyo o el del médico judio? ¿Cómo probar que Maimónides planea matarme?"

"Es muy simple, Majestad: cuando ambos traigamos nuestros venenos, tomaré de buena gana el de mi rival y luego el mio y no me sucederá nada. Luego Maimónides beberá mi veneno y luego el suyo y morirá. Entonces quedará demostrado que no era fiel al reino y que conspiraba en su contra".

"Esto significa que perderé a uno de ustedes, pero entonces sabré quién es mi verdadero amigo", dijo el monarca.

Al día siguiente el Sultán ordenó que ambos médicos se presentaran en el palacio.

"Mis queridos amigos, anoche tuve un extraño sueño, se presentó ante mí un profeta y me dijo que uno de ustedes planeaba envenenarme. Ahora bien, no hace falta que me interrumpan; sé que ambos lo negarán y que tal vez ambos tengan razón. Sin embargo, no puedo ignorar este mensaje. ¿Pueden preparar para mí un antidoto que neutralice cualquier veneno existente?"

"Claro que si", exclamaron ambos médicos.

Entonces Saladino les dijo: "Para saber cual antídoto es el más efectivo, haremos una pequeña prueba. Mañana, ambos traerán sus preparados, luego dividiremos cuidadosamente cada preparado en dos partes y cada uno beberá el preparado del otro y luego el suyo".

"Majestad eso mataría a mi amigo acá parado", dijo Maimónides.

"Parece que mi amigo Maimónides quiere librarse de la prueba, Su Majestad. En cuanto a mi", dijo Hakim, "no tengo problema alguno en realizarla. Beberé con gusto su veneno y probaré que el mío puede neutralizarlo".

"Me alegra saber que ambos están tan seguros de si mismos, caballeros. Eso hará que la prueba sea justa, los veré mañana".

Mientras Maimónides regresaba a su casa intentaba entender qué se escondía detrás de todo esto. No tenía dudas que Hakim sabía que no podía preparar un veneno más poderoso que el suyo. Entonces, ¿por que correr semejante riesgo? Seguro tenía pensado algún truco.

Al llegar a su casa, Maimónides se encontró con la sala de espera llena de personas, como de costurnbre. Algunos eran pacientes, otros lideres de la comunidad y otros eran estudiosos que venían a consultar su interpretación de pasajes dificiles del Talmud. 
Maimónides saludó a todos con una sonrisa y pidió disculpas mientras comía algo. Tras la comida, atendió a los pacientes y luego habló con los líderes y eruditos. Cuando terminó con todos ya era el atardecer. Recitó sus plegarias, se sentó a estudiar Torá y a escribir. Finalmente se retiró a descansar a primeras horas de la madrugada completamente agotado.

Durante el día no había tenido tiempo para seguir pensando en la dificil prueba que tendría lugar al día siguiente en el palacio del sultán. Ahora acostado en su cama no podía dormirse... algo le decía que su vida corría peligro y que su rival Hakim estaba detrás del concurso de vida y muerte.

De pronto, Maimónides comenzó a entender lo que había pensado el tramposo de Hakim y lo que debía hacer para evitar sus consecuencias.

Recién entonces sintió calma y pronto se quedó dormido.

Maimónides se levantó temprano en la mañana y, tras recitar sus plegarias matutinas, dedicó algún tiempo a estudiar la Torá, tomó un ligero desayuno y a continuación se dirigió a su laboratorio y preparó una inofensiva mezcla de agua dulce y vino tinto. Luego montó en su burro y se dirigió al palacio.

Hakim ya estaba esperándolo allí muy ansioso por comenzar con el certamen cuanto antes. También el sultán estaba preparado.

A una señal del rey ambos volcaron aproximadamente la mitad del contenido de sus preparados dentro de botellas vacías que habían llevado con esa finalidad y entregaron cada uno su botella al otro.

"Tu turno Hakim", dijo el sultán.

Hakim no perdió tiempo y tragó la mezcla que había preparado Maimónides y luego la suya y espero firme de pie con un rostro triunfal que Maimónides hiciera lo mismo.

"Ahora es tu turno Maimónides", dijo el sultán.

Maimónides tragó lentamente la mezcla que había preparado Hakim y luego la suya. También él parecía encontrarse bien.

Durante algún tiempo los dos esperaron silenciosos y tensos. De pronto Hakim lanzó un grito de agonia y dolor, cayó al suelo y pronto estuvo muerto.

"Me alegra mucho mi querido Maimónides que te encuentres bien. Nunca dudé que eres el mejor médico de mi reino. En cuanto al miserable de Hakim, estoy muy contento que lo hayas matado"

"Pero yo no he hecho nada, lo hizo su propia mano", respondió Maimónides. 
"No comprendo", dijo el sultán.

"Permítame explicarle. Hakim sabia que yo podía preparar un veneno mucho más poderoso, de manera que ideó un plan para preverlo. Él bebería un veneno de acción lenta en su casa y traeria consigo algo inofensivo. Así cuando yo trajese algo que seguramente fuese más fuerte, él se curaría. Luego bebería su propia mezcla y nada le pasaría. Después en mi turno, yo bebería su preparado inofensivo y luego mi veneno y moriría."

"¡Perro traidor!" gritó el sultán, "Pero dime, ¿qué pasó finalmente?"

"Pues bien, sospechando su truco, también yo preparé una mezcla inofensiva".

El sultán pensó por un instante y luego echó a reír comprendiendo lo que había sucedido.

Finalmente dijo: "No solo eres él médico más grande, Maimónides, sino él más sabio de los hombres. De ahora en adelante además de mi médico serás mi consejero personal".

\section{LA GRANDEZA DEL RAMBAM}

En otra oportunidad, y con el propósito de desacreditar a Maimónides frente al sultán y su corte, los médicos egipcios llevaron un petitorio al rey diciendo que querían debatir con Rambam sobre medicina.

El rey sabía que los conocimientos de Rambam en el campo de la medicina eran muy amplios, por lo cual le pidió que aceptara la propuesta, ya que seguramente los vencería.

El debate se desarrolló largas horas y al final hubo diferentes opiniones entre las dos partes, en relación con la pregunta de si era posible curar a un ciego.

La opinión de Rambam fue que era posible curar a un ciego solo si perdió la vista después de nacer, mas quien nació ciego, no tenía curación.

Los médicos egipcios, en cambio, argumentaron que con "su gran sabiduría" podrian curar incluso a quien nació ciego y que estaban listos para demostrarlo.

Al final del debate se decidió, que si en el transcurso de los próximos ocho días traían los médicos un ciego de nacimiento y lo curaban, se consideraría que vencieron a Maimónides y podrían hacer con él lo que deseasen.

Salieron los médicos a la calle de la ciudad y buscaron a un hombre que habia perdido la visión después de su nacimiento. Después de larga búsqueda encontraron un joven de catorce años, que hacía un tiempo había perdido la visión.

Se acercaron a él los médicos y le preguntaron “¿Estás interesado en que te curemos?". "Seguro", contestó el joven con alegría. 
Le dijeron los médicos: "Lo haremos, pero con una sola condición: que digas delante del rey que eres ciego de nacimiento. También le dirás a tu madre y los vecinos que digan lo mismo".

Se alegró mucho el joven al escuchar las palabras de los médicos y corrió a contarle las novedades a su madre y también ella aceptó la condición. Los médicos la instruyeron acerca de lo que ella y sus vecinos tenían que decir.

Tomaron al joven y después de ocho días de tratamiento intensivo, lograron que el joven recuperara la vista.

Al término de los ocho dias, se presentó el Rambam frente al rey y llegaron los médicos con el joven ciego.

Dijeron los médicos: "Su majestad, hemos traído un joven que era ciego de nacimiento, de acuerdo al testimonio de su madre y sus vecinos, y lo hemos curado de su ceguera".

Preguntó el rey a la madre y a los vecinos, y éstos confirmaron las palabras de los médicos, diciendo que el joven sufría de ceguera congénita y que hacía unos días los médicos habían empezado a tratarlo y lo curaron.

Pudo comprobar el rey que la verdad estaba con los médicos y que era posible curar la ceguera congenita.

Se dirigió el rey a Rambam y le preguntó: "¿Qué puedes decir sobre esto? Nuestros médicos confirman que es posible curar a un ciego de nacimiento".

"Yo no creo que este joven fue ciego de nacimiento, debido a que la ceguera congénita no puede ser curada".

Maimónides solicitó el permiso del rey para retornar en pocos minutos y demostrar sus razones. Aceptó el rey y Rambam salió apresuradamente al mercado y compró siete papeles de diferentes colores y los trajo al palacio real.

Todos los presentes estaban desconcertados y no sabian qué pensaba hacer ...

Llamó Rambam al joven y le dijo: "Hijo mío, deseo preguntarte algo: ¿En este momento ves bien y puedes distinguir entre un objeto y otro?".

"Sí, puedo ver y distinguir claramente entre las cosas", contestó el joven.

Acto seguido, sacó Rambam los papeles de colores y le preguntó:

"¿Puedes distinguir entre los colores? Dime que color es cada uno de estos papeles".

"Este es rojo, el segundo verde, el tercero azul...", señaló el joven. 
En ese momento se dirigió Rambam al rey y dijo con una sonrisa: "Puede observar, Su Majestad, que los médicos, el joven, la madre y los vecinos mintieron al decir que el ciego no vio nunca luz".

El tey y los médicos siguieron atentamente las palabras de Rambam y éste continuó con voz segura y suave:

"Si fuera verdad que el joven era ciego congénito, ¿cómo supo distinguir entre los colores? Si supo el nombre de cada color, señal que el joven vio durante varios años y solo en una etapa posterior perdió la vista".

Al escuchar los médicos la prueba irrefutable de Rambam quedaron sin palabras y avergonzados delante del rey.

Quiso el rey castigarlos severamente por sus mentiras, pero el Rambam pidió que fuesen perdonados.

El nombre de Rabí Moshé Ben Maimón, se difundió por todo el mundo por su gran sabiduría y piedad con todos sus semejantes.

\section{Plegaria del Médico}

"D-s, llena mi alma de amor por el arte y por todas las criaturas. Aparta de mí la tentación de que la sed de lucro y la búsqueda de la gloria me influencien en el ejercicio de mi profesión. Sostén la fuerza de mi corazón para que esté siempre dispuesto a servir al pobre y al rico, al amigo y al enemigo, al justo y al injusto.

Haz que no vea más que al hombre en aquél que sufre. Haz que mi espiritu permanezca claro en toda circunstancia, pues grande y sublime es la ciencia que tiene por objeto conservar la salud y la vida de todas las criaturas.

Haz que mis enfermos tengan confianza en mí y en mi arte y que sigan mis consejos y prescripciones.

Aleja de sus lechos a los charlatanes, al ejército de parientes con sus mil consejos y a los vigilantes que siempre lo saben todo; es una casta peligrosa que hace fracasar por vanidad las mejores intenciones.

Concédeme, D-s mío, indulgencia y paciencia con los enfermos obstinados y groseros.

Haz que sea moderado en todo, pero insaciable en mi amor por la ciencia. Aleja de mi la idea que lo puedo todo. Dame la fuerza la voluntad y la oportunidad de ampliar cada vez más mis conocimientos, a fin de que pueda procurar mayores beneficios a quienes sufren.

Amén!"

Moisés Ben-Maimónides, el Español. 


\section{BIBLIOGRAFIA}

BAER, Yitzhak

Historia de los judios en España

Barcelona, Riopiedras, 1998.

\section{BLIDSTEIN GJ.}

"Where do we stand in the study of Maimonidean Halakhah?"

In: TWERSKY I. ed. Studies in Maimonides

Boston, Harvard University Press, 1990:1-30.

BORTZ, Jaime Elias

Maimónides. Biografia crítica y algunos aspectos metodológicos.[s.l], El Cid 2001 .

DIENSTAG JI, ed.

Studies in Maimonides and St. Thomas Aquinas

New York, Ktav Publishing, 1975.

HALKIN A, HARTMANN D. (trans.)

Crisis and Leadership: Epistles of Maimonides

Philadelphia/New York/Jerusalem, Jewish Publication Society of America, 1985.

HESCHEL AJ.

Maimonides - a Biography

New York, Farrar/Straus/Giroux, 1982.

JIMÉNEZ LOZANO José

Sobre judios, moriscos y conversos. Convivencia y ruptura de las tres castas

Valladolid, Ámbito, 2002.

KOTTEK S.

"Maimonides on the perfect physician".

In: ROSNER F, KOTTEK S, eds. Moses Maimonides - Physician, Scientist, and Philosopher New Jersey/London, Jason Aronson Inc., 1993:25-32.

KRAEMER JL.

"Maimonides on the philosophic sciences in his treatise on the art of logic"

In: KRAEMER JL, ed. Perspectives on Maimonides: Philosophical and Historical Studies

Oxford, Oxford University Press, 1991:77-104.

\section{KREISEL $\mathrm{H}$.}

Maimonides' Political Thoughts - Studies in Ethics, Law and the Human Ideal Albany, State University of New York Press, 1991. 
LACAVE, José Luis

Guía de la España Judia: itinerarios de Sefarad

Córdoba, El Almendro, 2000.

LANGERMANN YT.

"The mathematical writings of Maimonides"

Jewish Quarterly Review 1984/5:75:57-65.

LEIBOWITZ JO.

“Maimonides' A phorisms” Korot 1955;1:213-19.

LEIBOWITZ JO.

"The Latin Translation of Maimonides' Aphorisms"Korot 1973;6:273-81.

\section{MAIMÓNIDES}

Guia de los perplejos

$4^{\mathrm{a} e d .}$ Madrid, Trotta, 2005.

Maimonides' commentary on the Mishnah,

Introduction; introduction to Sanhedrin X; introduction to Avot.

Maimonides's letter to Rabbi Yehonathan Ha-Kothen of Lunel.

Maimonides' Mishneh Torah, Laws of the Foundations of the Torah, $2: 1-2 ; 4: 12$.

MAIMONIDES Moses

Guide of the Perplexed

Translated with Introduction and Notes by Pines S. University of Chicago Press, 1963.

MUNTNER S.

Moshe ben Maimon (Maimonides) Medical Works

(Hebrew). Jerusalem, Mossad Harav Kook, 1965:IV:157.

ROSNER F. Abraham

Maimonides' Wars of the Lord and the Maimonidean Controversy

Haifa, Maimonides Research Institute, 2000.

ROSNER F.

Medicine in the Mishneh Torah of Maimonides

New York, Ktav Publishing, 1984.

ROTH L.

Judaism - a Portrait

New York, Viking Press, 1960:46. 
SÁENZ-BADILLOS (Ed.)

$J$ udios entre árabes y cristianos

Córdoba, El Almendro, 2000.

SILVER DJ.

Maimonidean Criticism and the Maimonidean Controversy

Leiden, EJ Brill, 1965.

PELAEZ DEL ROSAL Jesús, editor

Sobre la vida y obra de Maimónides: I Congreso Internacional (Córdoba. 1985)

Córdoba, El Almendro, D.L. 1991.

\section{TWERSKY I.}

Introduction to the Code of Maimonides (Mishneh Torah)

New Haven, Yale University Press, 1980:259-323.

VALDEÓN BARUQUE, Julio

Cristianos, musulmanes y judios en la España medieval. De la aceptación al rechazo

Valladolid, Ámbito, 2002.

WEISS, Raymond L.

Maimonides'Ethics: The Encounter of Philosophic and Religious Morality

University of Chicago Press, 1991. 